\title{
Population Continuity or Population Change: Formation of the Ancient Egyptian State
}

\author{
Sonia R. Zakrzewski ${ }^{\star}$ \\ Department of Archaeology, University of Southampton, Highfield, Southampton SO17 1BF, UK
}

KEY WORDS Egypt; craniometric variation; biodistance; population history; phenotypic diversity

\begin{abstract}
The origins of the ancient Egyptian state and its formation have received much attention through analysis of mortuary contexts, skeletal material, and trade. Genetic diversity was analyzed by studying craniometric variation within a series of six time-successive Egyptian populations in order to investigate the evidence for migration over the period of the development of social hierarchy and the Egyptian state. Craniometric variation, based upon 16 measurements, was assessed through principal components analysis, discriminant function analysis, and Mahalanobis $D^{2}$ matrix computation. Spatial and
\end{abstract}

The origins of the Egyptian state have long been debated, with, as a result of the prevailing diffusionist paradigms of the time (Armelagos and Mills, 1993), much early attention focusing on the ethnic affiliation or biological similarities of the early Dynastic (EDyn) groups. Purported changes in the archaeological sequence associated with the formation of the state were attributed to the population replacement as a result of the arrival of a "Dynastic Race" of invaders (Petrie, 1920, 1939; Winkler, 1938, 1939; Emery, 1961). More recently, Egyptologists have proposed a model for indigenous state formation, whereby three protostates developed and merged through military or other expansion (Trigger, 1983; Hassan, 1988; Bard, 1989, 1994; Kemp, 1989), while others have taken a more Afrocentrist approach (Diop, 1974; Bernal, 1987, 1991).

The invasion model for state formation usually involved the migration of a foreign population along the Wadi Hammamat from Asia (Winkler, 1938, 1939; Derry, 1956; Kantor, 1965), or along a northern Egyptian delta route (Bard, 1994). Evidence to support this hypothesis consists of pottery from regions such as Palestine (Kantor, 1965), and Near Eastern turquoise and shells (Arkell, 1975) found within Predynastic Egyptian sites. Furthermore, Uruk cultural markers are found at sites in the delta (Bard, 1994). The process of State formation, therefore, has considered to have been affected, or even caused by new populations entering the Nile Valley (as proposed by Petrie and Winkler). This new group was considered to be either a small immigration (following Kantor, 1965) or a large-scale population replacement (following Petrie, 1920, 1939).

The later model of indigenous development is based upon both agriculture and warfare, with the Upper Egyptian nomes or districts conquering the Northern nomes in Lower Egypt. This model of state formation avoids population migrations along the Nile Valley, and is reliant only on in situ development by the indigenous population.

The current article assesses the biological affinities of a large sample of EDyn Egyptian crania and compares temporal relationships were assessed by Mantel and Partial Mantel tests. The results indicate overall population continuity over the Predynastic and early Dynastic, and high levels of genetic heterogeneity, thereby suggesting that state formation occurred as a mainly indigenous process. Nevertheless, significant differences were found in morphology between both geographically-pooled and cemetery-specific temporal groups, indicating that some migration occurred along the Egyptian Nile Valley over the periods studied. Am J Phys Anthropol 132:501-509, 2007. ๑2007 Wiley-Liss, Inc.

these with local preceding samples to establish whether any diachronic or synchronic morphological variation is found.

\section{PREVIOUS CRANIOMETRIC STUDIES}

A summary of the results of major previous studies is presented here; for further details see Keita (1995, 2004). The earliest morphological studies of Egyptian crania were chiefly concerned with the shape of certain anatomical complexes. These complexes, defined by extreme variants as geographic groups, were considered to be "racial types" (Warren, 1897; Fawcett and Lee, 1902; GiuffridaRuggeri, 1915; Pearson and Davin, 1924; Stoessiger, 1927; Woo, 1930; Morant, 1925, 1935, 1937; Jackson and Cave, 1937; Risdon, 1939; Derry, 1956; Nutter, 1958). For example, Randall-MacIver (1901), and Thomson and Randall-MacIver (1905), employing morphological observations, concluded that southern Predynastic Egyptians were a hybrid population, consisting of "Negroid" and non-"Negroid" (Semitic) elements. The pattern of variation in facial and nasal indices was similar for both sexes through all periods from the Predynastic to the Roman period. This, they argued, meant that the distribution could not be considered simply a result of normal varia-

Grant sponsors: The Wellcome Trust (Bioarchaeology Panel); St John's College, University of Cambridge; University of Durham (Addison Wheeler Fellowship); University of Southampton.

*Correspondence to: Dr. Sonia R. Zakrzewski, Department of Archaeology, University of Southampton, Highfield, Southampton SO17 1BF, UK. E-mail: srz@soton.ac.uk

Received 8 May 2006; accepted 12 December 2006

DOI 10.1002/ajpa.20569

Published online 12 February 2007 in Wiley InterScience (www.interscience.wiley.com). 
tion of a single type; rather they suggested the juxtaposition of two groups based upon the correlation between facial and nasal indices as the sole criterion for distinguishing these two racial groups. The first group were short or broad-faced and platyrhine, while the second group was long or narrow-faced and leptorhine. Morant (1925, 1935) argued that the Lower Egyptian type remained relatively unchanged from EDyn times to the Ptolemaic period, but that during this time the Upper Egyptian type changed, and as the vast majority of southern Dynastic crania fell between the two extremes of the "types", some form of transition must have occurred. Morant considered both types to represent very closely related populations; the differences between them could be due to evolution through selection or differing environments, or through the slow mingling of two different races. Risdon (1939) argued that the population of Upper Egypt underwent gradual change from the Badarian through to the 18th Dynasty, and that by the New Kingdom, one group had almost entirely replaced the other in Upper Egypt. ElliotSmith (1915-1916) defined as a "Brown Race" the autochthonous population of the Nile Valley, although GiuffridaRuggeri (1922) considered this confusing as it blurred Caucasian and African "types". Elliot-Smith considered the Brown Race to have been modified by "Negroes" in the south and by Near Eastern populations in the north. By contrast, Giuffrida-Ruggeri (1922) concluded that the Lower Egyptians were a Mediterranean white population while the Upper Egyptians were Ethiopians.

Falkenburger (1947), Strouhal (1971), and Angel (1972) all considered the southern Egyptian populations to be "Negroid" or hybrid in character, while the northern populations were more European-like. Wiercinski (1965) defined the basic or indigenous Egyptian type as being Badarian-like, but then said that this group was of Near Eastern origin. Other authors considered the Badarian to be a "Negroid" group (Morant, 1935, 1937; Nutter, 1958; Strouhal, 1971; Angel, 1972). Coon (1939) considered a Delta Predynastic sample to be less "Negroid" in character than southern populations.

Although there was some criticism of the racial typology underlying these studies (Myers, 1905, 1908; Batrawi, $1945,1946)$, most morphometric studies continued to employ the concept of two populations in Egypt, such as the Upper and Lower Egyptian types of Morant (1925) and Risdon (1939). Most authors suggested that the Upper Egyptian type (i.e. southern) had more "Negroid" traits that were gradually lost through time (Morant, 1925, 1935; Risdon, 1939; Batrawi, 1946). These studies also found that the southern populations tended to cluster with more southerly groups, e.g. Crichton (1966) found Naqada crania to be more "Negroid" than a later period sample from Gizeh, while Bräuer (1976) found that Nubian and early Egyptian series tended to cluster with more southern African groups.

Recent craniometric studies continue to note morphological differences between northern and southern Egyptian samples. Hillson (1978) referred to this as two distinct trends within his data set:

1. a northern and lower Egyptian tendency

2. a southern Egyptian and southern African trend.

In his work, the Upper Egyptians overlapped with southern African populations. Billy (1977) noted, from Penrose's C analyses, that the homogeneity of her Lower Egypt series contrasted with greater dispersion in Upper
Egypt with a constant morphological type being conserved through Dynastic times in the north. Keita (1990, 1992), through the use of discriminant function analysis (DFA), noted the overlap of southern Egyptians and some southern African series.

The earliest sample, the Badarian, frequently appears to be relatively distinct. This could be due to their very gracile nature (Gaballah et al., 1972), with very little development of the muscular relief; hence they have often been considered to have a generally "feminine" character (Strouhal, 1971). In early studies the Badarian sample were usually also described as having rather small absolute dimensions, especially in terms of breadth, horizontal circumference, and cranial capacity (Stoessiger, 1927; Morant, 1935). Stoessinger (1927) described the group as being distinct from Later Predynastic (LPD) populations through being more dolichocephalic and prognathic, somewhat narrower in the parietal region, and having shorter faces (and a lower nasal index). In contrast, Strouhal (1971) considered them to have high nasal indices. He also summarized them as being dolichocranial, orthocranial, mesenic to leptic, and chamaerrhine, i.e. having narrow, average height skulls with average to narrow upper faces, and a rather broad nose with marked prognathism. It is interesting to note that these biometrical studies led the investigators to consider the Badarian to be homogeneous, while the excavators (Brunton and Caton-Thompson) considered them to be heterogeneous (Strouhal, 1971). When Mahalanobis $D^{2}$ was used, the Naqadan and Badarian Predynastic samples exhibited more similarity to Nubian, Tigrean, and some more southern series than to some mid- to late Dynastic series from northern Egypt (Mukherjee et al., 1955). The Badarian have been found to be very similar to a Kerma sample (Kushite Sudanese), using both the Penrose statistic (Nutter, 1958) and DFA of males alone (Keita, 1990). Furthermore, Keita considered that Badarian males had a southern modal phenotype, and that together with a Naqada sample, they formed a southern Egyptian cluster as tropical variants together with a sample from Kerma.

Although the Badarian material is considered by biometricians to be homogeneous, this homogeneity may break down by the LPD period, and has certainly broken down by the EDyn period, e.g. the cranial material from the Royal Tombs sample at Abydos has a markedly heterogeneous appearance (Keita, 1992). Billy (1975) found little similarity between Predynastic samples, and even found that 1st Dynasty material from Abydos and El Amrah failed to cluster, and that the Royal Tombs material was morphologically distinct from all other EDyn period samples (Batrawi, 1946; Billy, 1975, 1977). Rösing (1990) also analyzed a large series of Upper Egyptian crania, and found greater morphological separation between Predynastic and historic Egyptian than between Predynastic Egyptian and Nubian groups.

In summary, most early craniometric studies concluded that there were two population groups inhabiting Egypt throughout the Predynastic period, and that the northern group (the Lower Egyptian type) replaced the more "Negroid" southern type during the Dynastic period. Most modern Egyptologists adopt a different view, who (even when arguing for a conquest of the country as the prime mover in the formation of the State (argue that the southern populations conquered the northern groups. More recent studies continue to show a geographic variation in morphology within Egyptian samples (as opposed to 


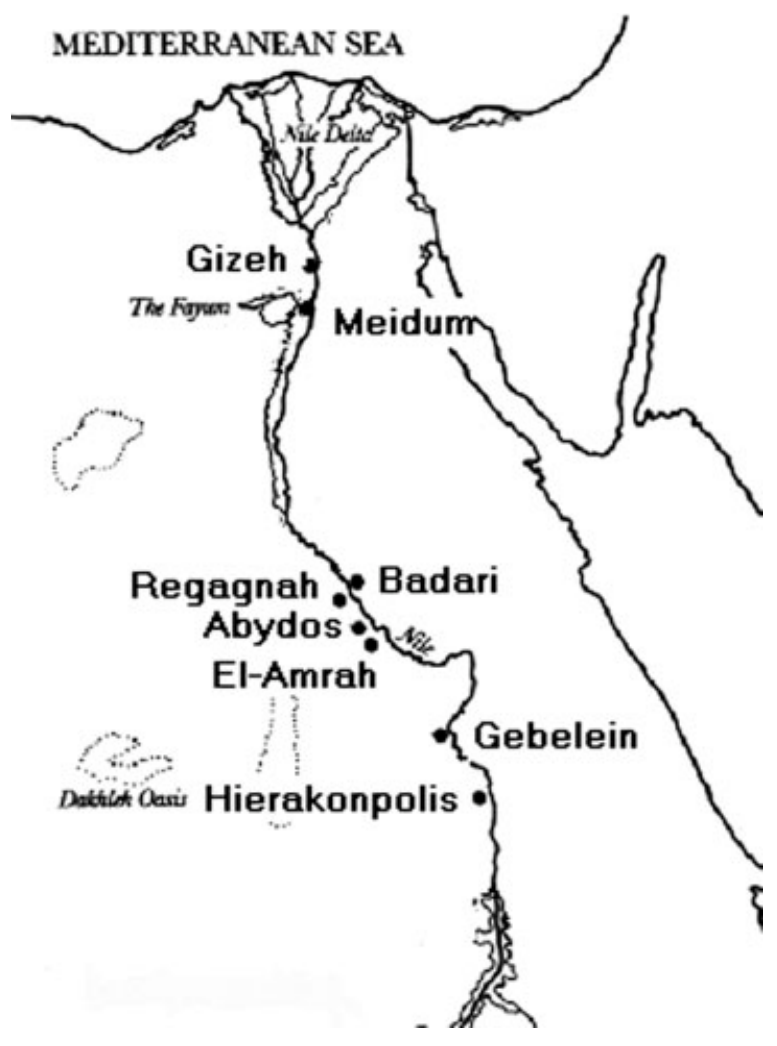

Fig. 1. Map of Egyptian sites sampled.

Nubian material). This variation may be due to migrations of people or to other local factors.

The current article aims to ascertain whether any trend-like or distinct change is seen in craniometric measurements over the period of state formation, as the former would suggest indigenous state development, whereas the latter would suggest a greater role for migration in the process. The current study concentrates upon the Predynastic and EDyn periods, but also includes assessment of the Badarian and Middle Kingdom (MK) populations for comparison purposes.

\section{MATERIALS AND METHODS}

Skeletal sampling was mainly restricted to sites from Middle and Upper Egypt so that all individuals would have experienced reasonably similar geographical and climatic conditions. Due to the lack of Old Kingdom (OK), skeletal remains from Upper Egypt and one series from Lower Egypt were also analyzed (Gizeh). Site locations are shown in Figure 1. Distances between sites are shown in Table 1.

The selection of skeletal material was mainly pragmatic. For most periods, all available material was assessed, although complete skeletons were preferred over crania alone, and complete crania were selected in preference to fragmentary material. Care was taken to maximize samples from all available time periods. The sampling was also limited by the selection of the material that had been removed from Egypt and thus available for study in museum and university collections. Many collections derive from early excavations, with only individuals of interest being shipped back to the European collector
TABLE 1. Spatial distance between the archaeological sites $(\mathrm{km})$

\begin{tabular}{lrrrrrrr}
\hline & Bad & AEA & Hrk & Med & Reg & Giz & Geb \\
\hline Bad & - & & & & & & \\
AEA & 106 & - & & & & & \\
Hrk & 253 & 147 & - & & & & \\
Med & 267 & 369 & 507 & - & & & \\
Reg & 84 & 23 & 170 & 349 & - & & \\
Giz & 333 & 433 & 569 & 65 & 413 & - & \\
Geb & 200 & 94 & 54 & 455 & 116 & 518 & - \\
\hline
\end{tabular}

Bad refers to El-Badari, AEA to Abydos El-Amrah, Hrk to Hierakonpolis, Med to Meidum, Reg to Regagnah, Giz to Gizeh, and Geb to Gebelein.

funding the excavation, and hence the material studied may not be completely representative of the cemetery population. Four collections were studied; the Duckworth Collection of the Department of Biological Anthropology in Cambridge, the Egyptian collection of the Natural History Museum in London, the Marro Collection of the Department of Anthropology and Biology in Turin, and the Reisner Collection of the Natural History Museum in Vienna.

A series of six time-period groups were studied, dating from the Badarian (c. $4000 \mathrm{BC}$ ) to the MK (c. $1900 \mathrm{BC}$ ). The periods studied were the Badarian, the Early Predynastic (EPD), the LPD, the EDyn, the OK, and MK. Samples (Table 2) were studied only if they could be reliably dated to one of the six periods. The dates in Table 2 are midpoint time period dates and generate a temporal distance matrix. For further details regarding the cemeteries, see Zakrzewski (2003). Analysis was limited to adult individuals, with maturity being determined on the basis of sphenooccipital fusion, full epiphyseal fusion, and complete eruption of the third molars.

Following Howells (1973, 1989), all individuals were assigned a sex, rather than being classified as 'sex unknown'. The sex of each individual was primarily determined from analysis of the pelvic region, by assessing the size of the pubic angle, the size of the greater sciatic notch, the curvature of the sacrum, noting the presence or absence of ventral arc and subpubic concavity, the relative lengths of the inferior ramus of the pubis, and the distance from the pubic tubercle to the acetabulum. Postcranial sex was compared with the cranially determined sex. Cranial sex was assessed from the degree of supraorbital and glabellar projection, the squareness of the anterior portion of the mandible, the flaring of the gonial region, the robustness and level of muscle development in the nuchal region, and other features, such as the general size of the cranium with respect to others in the sample. The size of the mastoids was considered, but all the Egyptian cranial material studied has relatively inflated mastoids as compared to other populations. For individuals for whom cranial material alone was available, comparisons were made with individuals of known sex to increase the reliability of the sexing method.

The techniques described by Howells $(1973,1989)$ and Lahr (1996) were employed in this study. A spreading caliper was used to take the measurements where both landmarks for a single measurement such as maximum cranial breadth (XCB) had to be instrumentally determined. A digital sliding caliper, with direct data entry to a portable computer, was used to measure directly from one landmark to another, e.g. upper facial height (NPH). 
TABLE 2. Sample information

\begin{tabular}{|c|c|c|c|c|c|}
\hline Time period & Date & $N$ & Cemetery site & Collection & $n$ \\
\hline Badari & $4000 \mathrm{BC}$ & 27 & El-Badari & Duckworth & 27 \\
\hline \multirow[t]{2}{*}{ EPD } & $3750 \mathrm{BC}$ & 53 & Abydos El-Amrah & London & 8 \\
\hline & & & Gebelein & Marro & 45 \\
\hline \multirow[t]{2}{*}{ LPD } & $3300 \mathrm{BC}$ & 41 & El-Amrah & London & 4 \\
\hline & & & Hierakonpolis & Duckworth & 37 \\
\hline EDyn & $2900 \mathrm{BC}$ & 48 & Abdyos El-Amrah & Duckworth and London & 48 \\
\hline \multirow[t]{3}{*}{$\mathrm{OK}$} & $2600 \mathrm{BC}$ & 56 & Meidum & London & 2 \\
\hline & & & Regagnah & London & 14 \\
\hline & & & Gizeh & Reisner & 40 \\
\hline MK & $1900 \mathrm{BC}$ & 22 & Gebelein & Marro & 22 \\
\hline
\end{tabular}

Dates for time periods are mid-point time dates for the samples studied. $N$ refers to the time period group sample size included in the current study, whereas $n$ refers to the cemetery sample size in the current study (i.e. $n$ is the breakdown of each time period group by cemetery).

\section{Data analysis}

SPSS 12.0 and PASSAGE 1.0 were used for statistical analysis. All variables were tested for normality using P$\mathrm{P}$ and $\mathrm{Q}-\mathrm{Q}$ plots, with a normal distribution being observed in all the variables selected for analysis. All data was then $Z$-scored within sexes (in order to adjust for sex-related size differences). Due to the rather small sample sizes of some time periods under consideration and the relatively fragmentary nature of the crania during these periods, analyses were performed on the pooled $Z$-scores. Given the fragmentary nature of the remains, to maximize the sample size (as crania lacking one measurement are removed from analyses), analysis of variance (ANOVA) was used to determine which variables exhibited significant differences between at least two of the time periods. Cut off-points from the ANOVA for variables for inclusion into further analyses were set at $P<0.001$ and $N \geq 300$ (thereby reducing the cranial sample size of the current study to 247). Details of measurements selected are provided in Table 3.

Principal components analysis (PCA) and DFA were undertaken. PCA is a form of factor analysis that aims to identify the underlying factors (variables) explaining the pattern within the set of observed variables, and is employed to ascertain which combination of variables best explain the variance seen within the ellipsoid of data points in multidimensional space. The importance of PCA in this study is to ascertain the morphological mapping of individuals, as overlap between temporal sample groups would therefore show morphological similarity. By contrast, the concept of DFA is to assign group membership from a number of predictors; thus in this study it has been used to assess whether craniometric variables can be used to predict the time period group membership of the cranial sample. The main aim is, therefore, to find the dimension or dimensions by which the groups differ and then derive classification functions from this to predict group membership. Successful development of these functions indicates that a degree of morphological differentiation exists between the samples.

The second part of the analysis was undertaken both on the time-period groups (where cemetery samples within each time period are pooled), and, where possible, on cemetery groups labeled by time period (such as the OK assemblage from Regagnah and the OK assemblage from Gizeh). Mahalanobis $D^{2}$ distances were calculated between the time-period groups and between the cemetery-sample groups. The Mahalanobis $D^{2}$ value between samples is used as a proxy for the genetic or biological distance
TABLE 3. Description of variables selected for analysis

\begin{tabular}{ll}
\hline Variable & \multicolumn{1}{c}{ Description } \\
\hline NOL & Maximum cranial length, measured from nasion \\
BNL & Basion-nasion length (subnasal prognathism) \\
BBH & Basion-bregma height \\
XCB & Maximum cranial breadth \\
XFB & Maximum frontal breadth \\
STB & Bistephanic breadth \\
AUB & Biauricular breadth \\
ASB & Biasterionic breadth \\
NPH & Upper facial height \\
NLH & Nasal height \\
FMB & Fronto-malar breadth (midfacial breadth) \\
NAS & Nasion subtense (midfacial prognathism) \\
EKB & Biorbital breadth \\
DKB & Interorbital breadth \\
WMH & Cheek height \\
SOS & Supraorbital projection \\
\hline
\end{tabular}

All variables measured to nearest $\mathrm{mm}$.

between those samples. Due to their proximity (less than $10 \mathrm{~km}$ apart), material from Abydos and El-Amrah were pooled to form one "cemetery" sample. In addition, due to low cemetery sample sizes, the LPD material from Abydos El-Amrah and the OK material from Meidum were not analyzed as separate cemeteries. The pattern of temporal separation and geographic distance or isolation may affect the pattern of between-sample $D^{2}$ distances. If an isolation by distance model applies to the Egyptian samples studied, the expectation is that genetic or phenetic distance (in this case $D^{2}$ values) and spatial distance should be positively correlated, whereas genetic distance and temporal distance should be negatively correlated, as described and observed by Konigsberg (1990). Due to the internal structure of the biological distance, temporal distance and spatial distance matrices (because they are distance matrices, their elements are nonindependent), regression testing of one on another requires modification to simple linear regression, such as through the use of Mantel and Partial Mantel Tests. The latter test permits testing of two matrices, while controlling for the third. The potential correlations tested were the relationship between biological distance and time period (for the pooled time period samples), and between biological distance and both temporal distance and geographic distance for the cemetery samples. The Partial Mantel Test tests for correlations between biological distance $\left(D^{2}\right)$ and temporal distance while controlling for geographic distance between the cemetery samples. A second Partial Mantel 
TABLE 4. Component loadings from principal components analysis

\begin{tabular}{llrrr}
\hline Variable & PC 1 & PC 2 & PC 3 & PC 4 \\
\hline FMB & 0.759 & 0.368 & 0.305 & -0.036 \\
AUB & 0.737 & -0.137 & 0.125 & 0.245 \\
NOL & 0.732 & 0.037 & -0.054 & -0.330 \\
NLH & 0.691 & 0.015 & -0.527 & 0.271 \\
XFB & 0.675 & -0.568 & 0.223 & -0.056 \\
EKB & 0.674 & 0.378 & 0.378 & -0.024 \\
NPH & 0.654 & 0.046 & -0.547 & 0.299 \\
BNL & 0.631 & 0.281 & -0.245 & -0.460 \\
ASB & 0.553 & -0.195 & 0.188 & 0.124 \\
WMH & 0.533 & 0.228 & -0.225 & 0.340 \\
BBH & 0.492 & -0.186 & -0.328 & -0.430 \\
STB & 0.572 & -0.593 & 0.268 & -0.071 \\
XCB & 0.583 & -0.593 & 0.043 & 0.049 \\
NAS & 0.437 & 0.536 & -0.060 & -0.239 \\
DKB & 0.350 & 0.402 & 0.463 & 0.086 \\
SOS & 0.305 & 0.302 & 0.167 & 0.317 \\
\hline
\end{tabular}

Test was used to test for correlations between biological distance and geographical distance while controlling for temporal distance (between the same cemetery samples). These analyses were undertaken using PASSAGE 1.0. This software program was developed by Dr M Rosenberg and is kindly made available by him (http://www. passagesoftware.net/) (Rosenberg, 2001).

\section{RESULTS}

PCA derived four components, cumulatively explaining $64.6 \%$ of the variance seen within the craniometric measurements (Table 4 for component loadings). Although no clear separation between the samples was seen (Fig. 2, plotting out the first two components), the EDyn and OK samples were generally longer vaulted with broader midfaces than the earlier samples (indicated by their position relatively high on PC1). The Badarian generally exhibit the greatest facial prognathism of the samples studied (demonstrated by their relatively high position on PC2). Despite their small sample size, and general lack in facial prognathism, the MK appear very morphologically heterogeneous (as indicated by their location in all quadrants of the plot). All individuals located at the extremes of the axes derive from the OK, suggesting morphological heterogeneity in this period.

Despite the overall morphological similarity (as determined from the overlapping nature) of these Egyptian samples (Fig. 2), morphological differences do exist between the time periods. DFA derived five functions, which together correctly classified $44.5 \%$ of the crania into their temporal group (Table 5). Importantly, although only $45 \%$ of crania were correctly classified by DFA, where misclassification occurred, the crania were generally misclassified into temporally adjacent samples (e.g. the Badarian misclassified as EPD). This implies some degree of morphological continuity across successive time periods. Most correct classifications were of the EDyn and most misclassifications were of the MK sample, suggesting some morphological homogeneity within the first sample and more heterogeneity in the later sample.

Mahalanobis $D^{2}$ distances were calculated between all the time periods (Table 6) and used as a proxy for genetic or biological distance between time periods. Most of the $D^{2}$ values were significant (that is, significantly greater

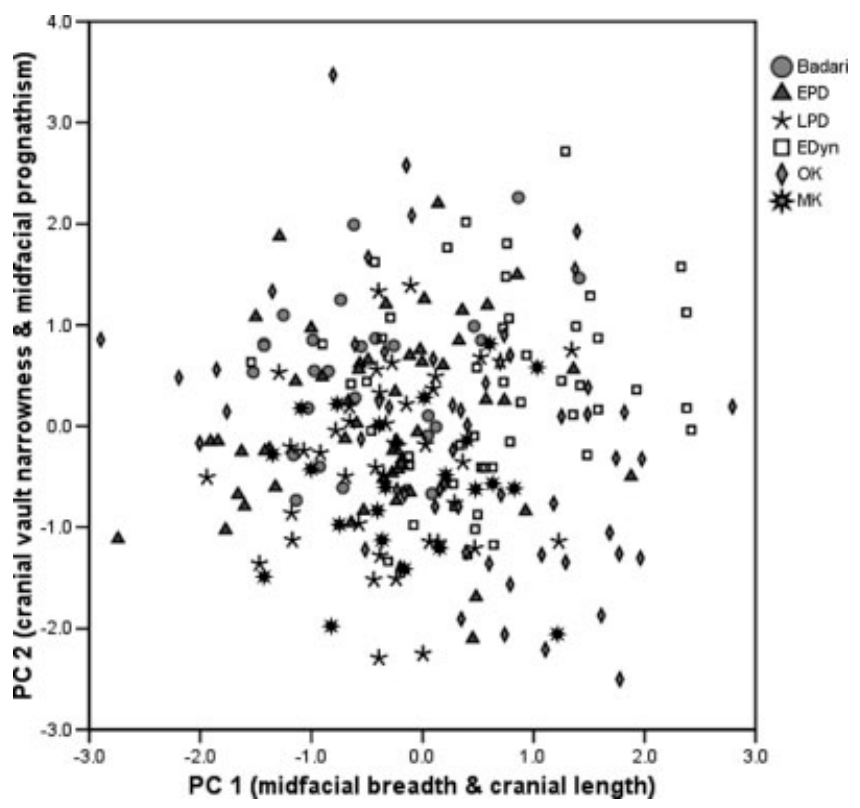

Fig. 2. Plot of the first two components derived, explaining $36.1 \%$ and $12.9 \%$ of the variance seen within the crania.

TABLE 5. Percentage classification of crania from DFA

\begin{tabular}{lcrrrrrr}
\hline \multirow{2}{*}{$\begin{array}{l}\text { Original } \\
\text { period }\end{array}$} & \multicolumn{6}{c}{ Predicted time period group membership (\%) } \\
\cline { 2 - 8 } & Badari & EPD & LPD & EDyn & OK & MK & Total \\
\hline Badari & $\mathbf{4 0 . 7}$ & 40.7 & 7.4 & 3.7 & 7.4 & 0 & 100.0 \\
EPD & 9.4 & $\mathbf{5 4 . 7}$ & 15.1 & 7.5 & 11.3 & 1.9 & 100.0 \\
LPD & 0 & 24.4 & $\mathbf{4 3 . 9}$ & 4.9 & 22.0 & 4.9 & 100.0 \\
EDyn & 2.1 & 8.3 & 4.2 & $\mathbf{7 2 . 9}$ & 10.4 & 2.1 & 100.0 \\
OK & 7.1 & 16.1 & 16.1 & 19.6 & $\mathbf{3 7 . 5}$ & 3.6 & 100.0 \\
MK & 0 & 22.7 & 4.5 & 0 & 63.6 & $\mathbf{9 . 1}$ & 100.0 \\
\hline
\end{tabular}

Correct classifications are marked in bold. Each row indicates the original time period group to which the crania belong, whereas each column indicates the group to which they have been classified by DFA on the basis of their morphology.

than 0), with all those relating to the Badarian, EPD, and EDyn time periods demonstrating significance at $P<$ 0.001 . There is no significant genetic (phenetic) distance between the pooled OK and MK samples. No significant correlation was found between temporal distance and the $D^{2}$ values (biological-temporal correlation $=0.0715$, n.s.).

Mahalanobis $D^{2}$ distances were also calculated between the cemetery groups by time period (Table 7). Again, most of the $D^{2}$ values were significant, with all those relating to the Badarian, from El-Badari, and the EDyn, from Abydos El-Amrah, demonstrating significance at $P<$ 0.001 . The partial correlation between biological distance and geographic distance between the cemeteries, controlling for time difference, is -0.3674 (n.s.). Controlling for geographic distance, the correlation between biological distance and time is -0.1692 (n.s.). A positive spatial-biological distance correlation would be expected under an isolation by distance model. Genetic distances between samples, as estimated here through $D^{2}$ distances, show no relationship with spatial distances between samples. A negative temporal correlation with genetic distance would also be expected under an isolation by distance model. Although this has been found within these samples, the correlation is very small and not statistically significant. 
TABLE 6. Mahalanobis $D^{2}$ distances between time periods (cemeteries pooled)

\begin{tabular}{|c|c|c|c|c|c|c|}
\hline & Badari & EPD & LPD & EDyn & OK & MK \\
\hline Badari & - & & & & & \\
\hline EPD & $2.6720 * * *$ & - & & & & \\
\hline LPD & $4.7414 * * *$ & $2.0598 * * *$ & - & & & \\
\hline EDyn & $6.1368 * * *$ & $3.6136 * * *$ & $4.8140 * * *$ & - & & \\
\hline $\mathrm{OK}$ & $3.2288^{* * * *}$ & $2.0806^{* * * *}$ & $1.4898 * *$ & $2.7859 * * *$ & - & \\
\hline MK & $3.9096 * * *$ & $2.6124^{* * * *}$ & $1.9551^{*}$ & $5.2559 * * *$ & 1.5156 n.s. & - \\
\hline
\end{tabular}

*Mahalanobis $D^{2}$ difference is significantly different at $P<0.05$, ** significant at $P<0.01$, ***significant at $P<0.001$.

TABLE 7. Mahalanobis $D^{2}$ distances between cemeteries by time periods

\begin{tabular}{|c|c|c|c|c|c|c|c|c|}
\hline & BadariBad & EPDAEA & EPDGeb & LPDHrk & EDynAEA & OKReg & OKGiz & MKGek \\
\hline BadariBad & - & & & & & & & \\
\hline EPDAEA & $4.9300 * * *$ & - & & & & & & \\
\hline EPDGeb & $3.1307 * * *$ & $5.6983 * *$ & - & & & & & \\
\hline LPDHrk & $5.2093 * * *$ & $6.6072^{* * * *}$ & $2.4495^{* * * *}$ & - & & & & \\
\hline EDynAEA & $6.1368 * * *$ & $8.3303^{* * *}$ & $3.6352^{* * * *}$ & $4.8724 * * *$ & - & & & \\
\hline OKReg & $4.5089 * * *$ & $6.3718^{*}$ & $4.0244^{* * * *}$ & $5.2922 * * *$ & $4.3267 * * *$ & - & & \\
\hline OKGiz & 4.1670 **** & $7.0585^{* * *}$ & 2.8394 **** & $1.4803^{*}$ & $3.8032^{* * * *}$ & $5.3168^{* * * *}$ & - & \\
\hline MKGeb & $3.9096 * * *$ & $5.1111^{*}$ & $3.0283^{* * *}$ & 1.9295 n.s. & $5.2559 * * *$ & $5.7951^{* * *}$ & 1.4408 n.s. & - \\
\hline
\end{tabular}

*Mahalanobis $D^{2}$ difference is significantly different at $P<0.05$, ** significant at $P<0.01$, ***significant at $P<0.001$.

\section{DISCUSSION}

The development of the Egyptian state and the associated formation of hierarchical social organization occurred very rapidly within Egypt over the LPD and EDyn (Bard, 1989). If this process occurred as an entirely indigenous development with total population continuity, then little increase in morphological heterogeneity would be expected. In accordance with previous studies (Keita, 1990; Prowse and Lovell, 1996), the current study has shown the ancient Egyptians to exhibit both genetic heterogeneity and morphological similarity. The former is demonstrated by the significant $D^{2}$ values between the time period samples and the misclassification of the crania to groups by the DFA, while the latter is demonstrated by the overlapping nature of the data points in Figure 2.

Despite significant pairwise $D^{2}$ values between the time periods groups, no significant relationship was seen between these $D^{2}$ values and time for the pooled cemetery samples (Table 6). Furthermore, no significant relationship was found between the $D^{2}$ values and either temporal or geographic distance (when controlling for the other matrix) for the individual cemetery samples (Table 7). These results suggest that distinct morphological differences occur between the various samples, but that these differences are not patterned in either space or time. This implies that an isolation by distance model may not be appropriate for these groups (although isolation by distance on a smaller distance scale would be undetectable in this data). This result is in contrast with earlier craniometric studies that found some evidence for distinct northern and southern morphological patterns (Hillson, 1978; Keita, 1990, 1992). This lack of biological patterning by geographic distance between the cemetery sites may result from the large scale of geographic distance between the cemeteries in this study (Table 1). Isolation by distance may therefore operate at shorter distances than the geographic distances between these cemeteries and hence would be undetectable in the current data set.

\section{The Badarian population}

The Badarian crania have been characterized by their small and gracile nature (Stoessiger, 1927; Morant, 1935; Strouhal, 1971; Gaballah et al., 1972), and their relatively high degree of facial prognathism (Stoessiger, 1927). The current study supports this description (being placed low on PC1 in Fig. 2, as a result of their short cranial vaults and narrow faces). Furthermore, their phenotypic homogeneity (Fig. 2, Table 5) has been demonstrated. As a result of their facial prognathism, the Badarian sample has been described as forming a morphological cluster with Nubian, Tigrean, and other southern (or "Negroid") groups (Morant, 1935, 1937; Mukherjee et al., 1955; Nutter, 1958, Strouhal, 1971; Angel, 1972; Keita, 1990). Cranial nonmetric trait studies have found this group to be similar to other Egyptians, including much later material (Berry and Berry, 1967, 1972), but also to be significantly different from LPD material (Berry et al., 1967). Similarly, the study of dental nonmetric traits has suggested that the Badarian population is at the centroid of Egyptian dental samples (Irish, 2006), thereby suggesting similarity and hence continuity across Egyptian time periods. From the central location of the Badarian samples in Figure 2, the current study finds the Badarian to be relatively morphologically close to the centroid of all the Egyptian samples. The Badarian have been shown to exhibit greatest morphological similarity with the temporally successive EPD (Table 5). Finally, the biological distinctiveness of the Badarian from other Egyptian samples has also been demonstrated (Tables 6 and 7).

\section{Formation of the Egyptian state}

Contra early Egyptologists (Petrie, 1920, 1939; Emery, 1961; Kantor, 1965), archaeological continuity is currently postulated between the Predynastic periods and the EDyn (Hassan, 1988; Kemp, 1989; Bard, 1989, 1994; Midant-Reynes, 2000a). Although the EDyn samples (both EDyn and OK) show morphological similarities with the preceding populations (Fig. 2), each sample does exhibit 
certain distinct characteristics. Lying high on PC1 in Figure 2, the EDyn sample and OK samples have relatively longer and broader cranial vaults. Furthermore the EDyn sample is characterized by their relatively broad faces, thereby allowing successful group delineation by DFA (Table 5). In concordance with Keita (1990), the EDyn crania studied also demonstrated morphological heterogeneity, with the small number of crania that are misclassified, being misclassified by DFA into all potential time periods. Significant genetic pairwise differences are found not only between the EDyn and all other pooled cemetery time periods (Table 6), but also between the EDyn sample and all single cemetery samples (Table 7). These results suggest that the EDyn do form a distinct morphological pattern. Their overlap with other Egyptian samples (in PC space, Fig. 2) suggests that although their morphology is distinctive, the pattern does overlap with the other time periods. These results therefore do not support the Petrie concept of a "Dynastic race" (Petrie, 1939; Derry, 1956). Instead, the results suggest that the Egyptian state was not the product of mass movement of populations into the Egyptian Nile region, but rather that it was the result of primarily indigenous development combined with prolonged small-scale migration, potentially from trade, military, or other contacts.

\section{The Middle Kingdom}

The MK sample was studied as a potential out-group for comparison with the Predynastic and EDyn periods. With the increased size of the Egyptian population by this period (Butzer, 1976; Brewer and Teeter, 1999), greater morphological heterogeneity was predicted to be found. Figure 2 indicates that, despite the small sample size, craniometric heterogeneity is found as the MK individuals are placed in all quadrants of the plot. Furthermore, discriminant functions were not successful at morphologically proscribing this sample (Table 5). In concordance with this, the MK sample exhibited fewest significant pairwise biological distances with other samples (Tables 6 and 7). The sample studied originates from Gebelein in Upper Egypt. Interestingly, the only other sample deriving from Gebelein, an EPD sample, was found to be significantly biologically distant to the MK sample (Table 7). This result suggests that there is no simple biological population continuity at Gebelein. Stele indicate that Nubian mercenaries lived, married, died, and were buried at this site over the MK period (Fischer, 1961). Previous research has suggested that this sample may include some of these Nubians (Zakrzewski, 2003). If Nubians had been integrated into the Egyptian population in the MK but not in preceding periods, then one would expect to see higher phenotypic variance in the MK than in the EDyn and OK. This cannot be ascertained from the current analysis, but must remain a topic for future research.

\section{Social context of the samples}

This study concentrated upon the period of state formation. The region at the center of this process was the Abydos region (Wilkinson, 1999) and the samples selected derive mainly from this area. Due to its geographic location, Abydos was able to control trade and raw material resources over the LPD and EDyn periods (Bard, 1994).

Like Abydos, during the OK, Gizeh was also in an area of greater control of trade, and therefore formed a potential magnet area for rural to urban migration. The OK material from Gizeh may therefore have greater internal social differentiation than the OK material from the more rural sites of Regagnah and Meidum. Unfortunately the OK sample from Meidum was poorly preserved and so most was unsuitable for the current analysis. The OK cemetery samples were found to be biologically distant from each other (Table 7). This may represent social differences between the samples. This hypothesis has been used to account for differences between other Egyptian samples, such as the apparent distinctiveness of samples from Predynastic Naqada (Johnson and Lovell, 1994; Prowse and Lovell, 1996), and from MK Lisht (Irish, 2006).

Social diversity and hierarchy, demonstrated from funerary contexts, increases through the Predynastic periods (Bard, 1989). During the EPD, an increase in social diversity is suggested from the graves and funerary offerings (Midant-Reynes, 2000b). Social hierarchy, as characterized by a dramatic increase in the number of funerary offerings, developed during the LPD (Castillos, 1983; Midant-Reynes, 2000a). It is thus possible that in the straight time period analysis, despite pooling samples from several sites, the low levels of morphological diversity noted in the EPD and LPD samples may result from sampling selection of individuals from limited segments of society. By contrast, postcranial analysis of these same samples demonstrated the greatest sexual dimorphism and thus greatest potential social ranking difference over the EPD and LPD (Zakrzewski, 2003).

The cranial material studied originated from a variety of funerary contexts (for detailed descriptions of the cemeteries, see Zakrzewski, 2003; Keita and Boyce, 2006). Pooling material in this manner reduces the likelihood of bias due to selection of only individuals from certain social groups. The only temporal samples to derive from only one cemetery are the Badarian and the MK. Periods of key interest to the current study, i.e. those over the period of state formation (EPD, LPD, EDyn, and OK), derived from more than one cemetery and hence may include individuals from across social ranks. The current study has shown this approach to be problematic as significant biological distance was found between cemeteries from the same time period (Table 7). Greater distance was found between the OK material from Regagnah and Gizeh than between the EPD material from Abydos ElAmrah and Gebelein. This may reflect differences in internal social organization and social ranking (as discussed above), the greater geographic distance between the later period sites, or it may reflect changes in the Egyptian population within the Dynastic period resulting from migration.

\section{CONCLUSIONS}

The analyses of the crania studied suggest that genetic continuity occurs over the Egyptian Predynastic and EDyn periods. The study also indicates that a relatively high level of genetic differentiation was sustained over this time period. This evidence suggests that the process of state formation itself may have been mainly an indigenous process, but that it may have occurred in association with in-migration to the Abydos region of the Nile Valley. This potential in-migration may have occurred particularly during the EDyn and OK. A possible explanation is that the Egyptian state formed through increasing control of trade and raw materials, or due to military actions, potentially associated with the use of the Nile Valley as a 
corridor for prolonged small scale movements through the desert environment.

Using Mahalanobis $D^{2}$ values as a proxy for genetic or phenetic distance, significant genetic distances were found between time period groups and between cemetery groups. No conclusive linear relationship was found from any of the regressions of genetic distance on temporal distance (for the pooled time period groups), genetic distance on temporal distance (controlling for spatial distance), or genetic distance on spatial distance (controlling for time) for the cemetery groups. These results indicate that the biological patterning of the Egyptian population varied across time, but that no simple and consistent temporal or spatial trends could be discerned.

The Badarian is shown to be a genetically homogeneous sample, characterized by short cranial vaults and significant subnasal prognathism. The homogeneity of the Badarian mirrors previous cranial (Stoessiger, 1927; Morant, 1935; Strouhal, 1971; Gaballah et al., 1972) and postcranial studies (Zakrzewski, 2003). Due to their placement in all sectors of Figure 2, later groups are shown as being more phenotypically heterogeneous. Furthermore, as a result of its long broad vaults and broad faces, the EDyn sample appears morphologically distinct relative to the other temporal groups.

Due to the relatively small sample sizes arising from the fragmentary nature of some of the crania and the lack of skeletal material that cross-cuts all social ranks within each time period, these results must remain provisional and indicative. Further research on recently excavated material, especially from the Delta area, is therefore required in order to further address the issues raised.

\section{ACKNOWLEDGMENTS}

The author thanks all curators, including M. Bellatti, R. Boano, R. Foley, L. Humphrey, R. Kruszynski, M. Lahr, E. Rabino-Massa, and M. Teschler-Nicola for allowing access to skeletons. Thanks also go to R. Foley, S. Hillson, M. Lahr, B. Kemp, and J. Rose for comments on earlier versions of this research. Lastly, the comments of the $A J P A$ editor Clark Larsen and the three reviewers were appreciated.

\section{LITERATURE CITED}

Angel JL. 1972. Biological relations of Egyptian and eastern mediterranean populations during pre-dynastic and dynastic times. J Hum Evol 1:307-313.

Arkell AJ. 1975. The prehistory of the Nile valley. Leiden: E. J. Brill.

Armelagos GJ, Mills JO. 1993. Palaeopathology as science: the contribution of Egyptology. In: Davies WV, Walker R, editors. Biological anthropology and the study of Ancient Egypt. London: British Museum Press. p 1-18.

Bard KA. 1989. The evolution of social complexity in Predynastic Egypt: an analysis of the Naqada cemeteries. J Mediterr Archaeol 2:223-248.

Bard KA. 1994. From farmers to Pharaohs. Sheffield: Sheffield Academic Press.

Batrawi A. 1945. The racial history of Egypt and Nubia. J R Anthropol Inst 75:81-101.

Batrawi A. 1946. The racial history of Egypt and Nubia. II. The racial relationships of the ancient and modern populations of Egypt and Nubia. J R Anthropol Inst 76:131-156.

Bernal M. 1987. Black Athena: the Afroasiatic roots of classical civilization, Vol 1: The fabrication of Ancient Greece, 17851985. London: Free Association Books.
Bernal M. 1991. Black Athena: the Afroasiatic roots of classical civilization, Vol 2: The archaeological and documentary evidence. New Brunswick, NJ: Rutgers University Press.

Berry AC, Berry RJ. 1967. Epigenetic variation in the human cranium. J Anat 101:361-379.

Berry AC, Berry RJ. 1972. Origins and the relationships of the ancient Egyptians. J Hum Evol 1:199-208.

Berry AC, Berry RJ, Ucko P. 1967. Genetical change in ancient Egypt. Man 2:551-568.

Billy G. 1975. Les grands courants du peuplement ÉgyptoNubien jusqu'à l'époque Romaine. L'Anthropologie 79:629657.

Billy G. 1977. Population changes in Egypt and Nubia. J Hum Evol 6:697-704.

Bräuer G. 1976. Morphological and multivariate analysis of human skeletons from Iron age graves northeast of Lake Eyasi (Tanzania). Homo 27:185-196.

Brewer DJ, Teeter E. 1999. Egypt and the Egyptians. Cambridge: Cambridge University Press.

Butzer KW. 1976. Early hydraulic civilization in Egypt: a study in cultural ecology. Chicago: University of Chicago Press.

Castillos JJ. 1983. A study of the spatial distribution of large and richly endowed tombs in the Egyptian predynastic and early dynastic cemeteries. Toronto: Benben Publications.

Coon CS. 1939. The races of Europe. New York: Macmillan.

Crichton JM. 1966. Papers of the Peabody museum of archaeology and ethnology, Vol. 57: A multiple discriminant analysis of Egyptian and African Negro crania. Cambridge, MA: Peabody Museum. p 45-67.

Derry DE. 1956. The dynastic race in Egypt. J Egypt Archaeol 42:80-85.

Diop CA. 1974. The African origin of civilization: myth or reality. Chicago: Hill.

Elliot-Smith G. 1915-16. The influence of racial admixture in Egypt. Eugen Rev 7:163-183.

Emery WB. 1961. Archaic Egypt. London: Penguin.

Falkenburger F. 1947. La composition racial de l'ancienne Égypte. L'Anthropologie 51:239-250.

Fawcett CD, Lee A. 1902. A second study of the variation and correlation of the human skull, with special reference to the Naqada crania. Biometrika 1:408-467.

Fischer HG. 1961. The Nubian mercenaries of Gebelein during the first intermediate period. Kush 9:44-80.

Gaballah MF, El-Rakhawy MT, El-Eishi HI. 1972. On the craniological study of Egyptians in various periods. Anthropologie X:29-33.

Giuffrida-Ruggeri V. 1915. Were the pre-dynastic Egyptians Libyans or Ethiopians? Man 15:51-56.

Giuffrida-Ruggeri V. 1922. The actual state of the question of the most Ancient Egyptian populations. Harv Afr Stud 3:3-7.

Hassan FA. 1988. The predynastic of Egypt. J World Prehist 2:135-185.

Hillson SW. 1978. Human biological variation in the Nile Valley, in relation to environmental factors. Unpublished Ph.D. thesis, University of London, London.

Howells WW. 1973. Papers of the Peabody museum of archaeology and ethnology, Vol. 67: Cranial variation in man: a study by multivariate analysis of patterns of difference among recent human populations. Cambridge, MA: Peabody Museum.

Howells WW. 1989. Papers of the Peabody museum of archaeology and ethnology, Vol. 79: Skull shapes and the map: craniometric analyses in the dispersion of modern Homo. Cambridge, MA: Peabody Museum.

Irish JD. 2006. Who were the ancient Egyptians? Dental affinities among Neolithic through postdynastic peoples. Am J Phys Anthropol 129:529-543.

Jackson JWF, Cave AJE. 1937. The osteology: report on the human remains. In: Mond R, Myers $\mathrm{OH}$, editors. Cemeteries of Armant 1. London: Egyptian Exploration Society. p 144157.

Johnson AL, Lovell NC. 1994. Biological differentiation at Predynastic Naqada, Egypt: an analysis of dental morphological traits. Am J Phys Anthropol 93:427-433. 
Kantor HJ. 1965. The relative chronology of Egypt and its foreign correlations before the Late Bronze Age. In: Ehrich RW, editor. Chronologies in old world archaeology. Chicago: University of Chicago Press. $p$ 1-46.

Keita SOY. 1990. Studies of ancient crania from northern Africa. Am J Phys Anthropol 83:35-48.

Keita SOY. 1992. Further studies of crania from ancient northern Africa: an analysis of crania from first dynasty Egyptian tombs, using multiple discriminant functions. Am J Phys Anthropol 87:245-254.

Keita SOY. 1995. A brief review of studies and comments on Ancient Egyptian biological relationships. Int J Anthropol 10: $107-123$.

Keita SOY. 2004. Exploring northeast African metric craniofacial variation at the individual level: a comparative study using principal components analysis. Am J Hum Biol 16:679-689.

Keita SOY, Boyce AJ. 2006. Variation in porotic hyperostosis in the royal cemetery complex at Abydos, Upper Egypt: a social interpretation. Antiquity 80:64-73.

Kemp BJ. 1989. Ancient Egypt: anatomy of a civilization. London: Routledge.

Konigsberg LW. 1990. Analysis of prehistoric biological variation under a model of isolation by geographic and temporal distance. Hum Biol 62:49-70.

Lahr MM. 1996. The evolution of modern human diversity. Cambridge: Cambridge University Press.

Midant-Reynes B. 2000a. The prehistory of Egypt. Oxford: Blackwell.

Midant-Reynes B. 2000b. The Naqada period. In: Shaw I, editor. The Oxford history of ancient Egypt. Oxford: Oxford University Press. p 44-60.

Morant GM. 1925. A study of Egyptian craniology from prehistoric to roman times. Biometrika 17:1-52.

Morant GM. 1935. A study of predynastic Egyptian skulls from Badari based on measurements taken by Miss B. N. Stoessiger and Professor D. E. Derry. Biometrika 27:293-309.

Morant GM. 1937. The predynastic Egyptian skulls from Badari and their racial affinities. In: Brunton $G$, editor. Mostagedda and the Tasian culture. London: Quaritch. p 63-66.

Mukherjee R, Rao CR, Trevor JC. 1955. The ancient inhabitants of Jebel Moya (Sudan). Cambridge: Cambridge University Press.

Myers CS. 1905. Contribution to Egyptian anthropometry. II. The comparative anthropometry of the most ancient and modern inhabitants. J Anthropol Inst 35:80-91.

Myers CS. 1908. Contributions to Egyptian anthropology. J R Anthropol Inst 38:99-147.
Nutter MC. 1958. An osteological study of the Hominoidea. Unpublished Ph.D. thesis, Cambridge University, Cambridge.

Pearson K, Davin AG. 1924. On the biometric constraints of the human skull. Biometrika 16:328-363.

Petrie WMF. 1920. Prehistoric Egypt. London: Bernard Quaritch.

Petrie WMF. 1939. The making of Egypt. London: Sheldon Press.

Prowse TL, Lovell NC. 1996. Concordance of cranial and dental morphological traits and evidence for endogamy in ancient Egypt. Am J Phys Anthropol 101:237-246.

Randall-MacIver D. 1901. The earliest inhabitants of Abydos: a craniological study. Oxford: Clarendon.

Risdon DL. 1939. A study of the cranial and other human remains from Palestine excavated at Tell Duweir (Lachish) by the Wellcome-Marston Archaeological Research Expedition. Biometrika 31:99-166.

Rosenberg, MS. 2001. PASSAGE. Pattern analysis, spatial statistics, and geographic exegesis, Version 1.0. Department of Biology, Arizona State University, Tempe, AZ.

Rösing FW. 1990. Qubbet el Hawa und Elephantine. Stuttgart: Gustav Fischer Verlag.

Stoessiger BN. 1927. A study of the Badarian crania recently excavated by the British School of Archaeology in Egypt. Biometrika 19:110-150.

Strouhal E. 1971. Evidence of the early penetration of Negroes into prehistoric Egypt. J Afr Hist 12:1-9.

Thomson A, Randall-MacIver D. 1905. The ancient races of the Thebaid: being an anthropometrical study of the inhabitants of Upper Egypt. Oxford: Clarendon.

Trigger BG. 1983. The rise of Egyptian civilization. In: Trigger BG, Kemp BJ, O'Connor D, Lloyd AB, editors. Ancient Egypt: a social history. Cambridge: Cambridge University Press. p 170 .

Warren E. 1897. An investigation of the variability of the human skeleton, with special reference to the Nagada race. Philos Trans R Soc Lond [Biol] 189:135-227.

Wiercinski A. 1965. The analysis of racial structure of early dynastic populations in Egypt. Mater i Prace Antropol 71:3-48.

Wilkinson TAH. 1999. Early dynastic Egypt. London: Routledge. Winkler HA. 1938. Rock-drawings of southern Upper Egypt. London: Oxford University Press.

Winkler HA. 1939. Rock-drawings of southern Upper Egypt. London: Oxford University Press.

Woo TL. 1930. A study of seventy-one ninth dynasty Egyptian skulls from Sedment. Biometrika 22:65-93.

Zakrzewski SR. 2003. Variation in Ancient Egyptian stature and body proportions. Am J Phys Anthropol 121:219-229. 